\title{
Age-related Purkinje cell death is steroid dependent: ROR $\alpha$ haplo-insufficiency impairs plasma and cerebellar steroids and Purkinje cell survival
}

\author{
Sonja Janmaat • Yvette Akwa • Mohamed Doulazmi • Joëlle Bakouche • \\ Vanessa Gautheron • Philippe Liere • Bernard Eychenne • Antoine Pianos • \\ Paul Luiten • Ton Groothuis • Etienne-Emile Baulieu • Jean Mariani • \\ Rachel M. Sherrard • Florence Frédéric
}

Received: 18 August 2010 /Accepted: 16 December 2010 /Published online: 11 January 2011

(C) The Author(s) 2011. This article is published with open access at Springerlink.com

\begin{abstract}
A major problem of ageing is progressive impairment of neuronal function and ultimately cell death. Since sex steroids are neuroprotective, their decrease with age may underlie age-related neuronal degeneration. To test this, we examined Purkinje cell numbers, plasma sex steroids and cerebellar neurosteroid concentrations during normal ageing (wildtype mice, WT), in our model of precocious ageing $\left(\right.$ Rora $^{+/ s g}$, heterozygous staggerer mice in which
\end{abstract}

Sonja Janmaat and Yvette Akwa contributed equally to this work.

Rachel M. Sherrard and Florence Frédéric are co-senior authors.

S. Janmaat $\cdot$ M. Doulazmi $\cdot$ J. Bakouche $\cdot$ V. Gautheron $\cdot$

J. Mariani $\cdot$ R. M. Sherrard $(\bowtie) \cdot F$. Frédéric

UMR7102 Neurobiologie des Processus Adaptatifs,

UPMC Univ Paris 6,

75005 Paris, France

e-mail: rachel.sherrard@snv.jussieu.fr

S. Janmaat $\cdot$ M. Doulazmi $\cdot$ J. Bakouche $\cdot$ V. Gautheron

J. Mariani $\cdot$ R. M. Sherrard $\cdot$ F. Frédéric

UMR7102 Neurobiologie des Processus Adaptatifs, CNRS,

75005 Paris, France

Y. Akwa $\cdot$ P. Liere $\cdot$ B. Eychenne $\cdot$ A. Pianos $\cdot$

E.-E. Baulieu

INSERM U788 and Université Paris-Sud, Faculté de

Médecine, UMR-S788,

Le Kremlin-Bicêtre 94276, France expression of the neuroprotective factor $\operatorname{ROR} \alpha$ is disrupted) and after long-term hormone insufficiency (WT post-gonadectomy). During normal ageing (WT), circulating sex steroids declined prior to or in parallel with Purkinje cell loss, which began at 18 months of age. Although Purkinje cell death was advanced in WT long-term steroid deficiency, this premature neuronal loss did not begin until 9 months, indicating that vulnerability to sex steroid deficiency

S. Janmaat

Molecular Imaging and Electron Microscopy, University

Medical Centre,

Groningen 9700 AD, The Netherlands

S. Janmaat $\cdot$ P. Luiten $\cdot$ T. Groothuis

Department of Molecular Neurobiology and Biological

Psychiatry, University of Groningen,

9750 AA Haren, The Netherlands

J. Mariani

AP-HP, Hôpital Charles Foix, UEF,

94200 Ivry-sur-Seine, France 
is a phenomenon of ageing Purkinje neurons. In precocious ageing $\left(\mathrm{Rora}^{+/ s g}\right)$, circulating sex steroids decreased prematurely, in conjunction with marked Purkinje cell death from 9 months. Although Rora $^{+/ s g}$ Purkinje cells are vulnerable through their $\operatorname{ROR} \alpha$ haplo-insufficiency, it is only as they age (after 9 months) that sex steroid failure becomes critical. Finally, cerebellar neurosteroids did not decrease with age in either genotype or gender; but were profoundly reduced by 3 months in male Rora $^{+/ s g}$ cerebella, which may contribute to the fragility of their Purkinje neurons. These data suggest that ageing Purkinje cells are maintained by circulating sex steroids, rather than local neurosteroids, and that in $\mathrm{Rora}^{+/ \mathrm{sg}}$ their agerelated death is advanced by premature sex steroid loss induced by ROR $\alpha$ haplo-insufficiency.

Keywords Ageing $\cdot \mathrm{ROR} \alpha \cdot$ Cerebellum $\cdot$ Purkinje cells $\cdot$ Sex steroid hormones $\cdot$ Neurosteroids

\section{Introduction}

A major problem in the ageing nervous system is the progression of neuronal dysfunction, atrophy and cell death. One of the factors that have been implicated in this progressive neurodegeneration is the decrease in gonadal steroids with advancing age (Smith et al. 2005). However, because steroids can be generated in the brain de novo from cholesterol (neurosteroids), the relation between sex steroids and age-related neuronal degeneration remains unclear (Schumacher et al. 2003; Veiga et al. 2004). Such information is important given the equivocal neuropsychological benefits and known side effects of systemic steroid hormone replacement for both men and women (for review see Pike et al. 2009) and current research to develop strategies that augment neurosteroids as a potentially better neuroprotective treatment for the aged brain (Azcoitia et al. 2005).

Cerebellar Purkinje cells provide a model with which to investigate the relative roles of circulating sex steroids and neurosteroids in age-related neuronal death. Purkinje cells are vulnerable neurons that die during ageing in both humans and rodents (Rogers et al. 1984; Andersen et al. 2003; Zhang et al. 2010). As Purkinje cells age, there is initial synaptic dysfunction (Rogers et al. 1980; Woodruff-Pak et al. 2010) with associated motor and cognitive decline (Thouvarecq et al. 2001; Woodruff-Pak 2006) followed by dendritic atrophy (Quackenbush et al. 1990; Zhang et al. 2006) and finally cell death (Woodruff-Pak 2006; Zhang et al. 2006; Woodruff-Pak et al. 2010). Purkinje cells are also targets of sex steroid action, expressing sex steroid receptors (Qin et al. 2007) and being protected by oestrogens and progestins during development (Tsutsui 2008; Biamonte et al. 2009) and following injury (Jung et al. 2002; Ardeshiri et al. 2006; Kelley et al. 2008). Moreover, oestrogens and progesterone promote Purkinje cell dendritic growth, spine formation and synaptic responses (Smith et al. 1987; Sakamoto et al. 2001; Sasahara et al. 2007), parameters that are the first to decay during Purkinje cell ageing (Rogers et al. 1980; Quackenbush et al. 1990; Zhang et al. 2006, 2010). Therefore, it may be proposed that Purkinje cells of all ages respond to sex steroids and that their progression through synaptic dysfunction, dendritic atrophy and death is secondary to the decline of sex steroid support during ageing. However, because Purkinje cells also synthesise neurosteroids (Tsutsui et al. 2003), the impact of gonadal sex steroids on Purkinje cell death during ageing remains unknown.

A potential link between sex steroids and age-related Purkinje cell death arises from the heterozygous staggerer mouse $\left(\mathrm{Rora}^{+/ s g}\right)$, in which mutant ROR $\alpha$ (retinoic acid receptor-related orphan receptor alpha) does not function (Hamilton et al. 1996). In $\mathrm{Rora}^{+/ s g}$ mice, Purkinje cells undergo the same age-related degenerative changes as normal cells, only at a much younger age (Caston et al. 1995; Doulazmi et al. 1999; Hadj-Sahraoui et al. 2001; Caston et al. 2003, 2004). Although it has been proposed that premature atrophy and death of $\mathrm{Rora}^{+/ s g}$ Purkinje cells is intrinsic to the gene defect (Herrup and Mullen 1981), there is a gender difference in their Purkinje cell loss that occurs earlier in males (Doulazmi et al. 1999). This suggests that differences in sex steroidogenesis may underlie the premature degeneration of Rora $^{+/ s g}$ Purkinje cells. This premise is supported by the involvement of $\operatorname{ROR} \alpha$ in endocrine function; it regulates enzymes involved in sex steroid synthesis (Kang et al. 2007; Wada et al. 2008; Odawara et al. 2009) and homozygous staggerer mice, which do not have $\operatorname{ROR} \alpha$, have impaired reproductive capability (Feron and Baudoin 1992; Guastavino and Larsson 1992).

To test the hypothesis that gonadal steroids and neurosteroids are involved in age-related Purkinje cell 
death, we analysed Purkinje cell numbers and related them to plasma sex steroid and cerebellar neurosteroid concentrations during normal ageing (wild-type mice, WT). We then validated our theory experimentally: measuring sex steroids in a mouse model in which Purkinje cells are known to age prematurely $\left(\mathrm{Rora}^{+/ s g}\right.$ mice) and finally evaluating the role of steroids by examining the time-course of cell death following long-term sex steroid insufficiency post-gonadectomy. Our data reveal that circulating sex steroids fall in advance of or in parallel with Purkinje cell death during both normal and precocious ageing and that Purkinje cell death is advanced when there is sex steroid insufficiency. While cerebellar neurosteroids do not decrease with age they are profoundly reduced in male $\mathrm{Rora}^{+/ \mathrm{sg}}$ cerebella, which may enhance and/or explain the vulnerability of $\mathrm{Rora}^{+/ / s g}$ Purkinje cells in males. These data suggest that circulating sex steroids, rather than local neurosteroids, play an important neuroprotective role in the ageing cerebellum, which has important implications for treatment strategies of age-related neurodegenerative phenomena.

\section{Materials and methods}

\section{Animals}

Heterozygote staggerer $\left(\right.$ Rora $\left.^{+/ s g}\right)$ and WT mice were bred from heterozygous C57Bl/6 $\left(\right.$ Rora $\left.^{+/ s g}\right)$ pairs in our colony at the IFR 83 Biologie Integrative (Paris, France). Intact male and female WT and Rora $^{+/ s g}$ and gonadectomised WT mice were used for the measurements of Purkinje cell numbers and steroid concentrations at 3, 9, 13, 18 and 24 months of age. Females were randomly cycled. All efforts were made to minimise the number of animals used. Animals had access to food and water ad libitum and were housed under controlled temperature $\left(24 \pm 2^{\circ} \mathrm{C}\right)$ and a $14 / 10$ h light/dark cycle. All animal procedures were performed under the guidelines established by 'le Comité National d'Ethique pour les Sciences de la Vie et de la Santé' and the European Communities Council Directive of November 24, 1986 (86/609/EEC).

Genotype analysis

Genomic DNA was extracted from tail biopsies as previously described (Gautheron et al. 2009). Briefly, tissue was digested overnight at $55^{\circ} \mathrm{C}$ with proteinase $\mathrm{K}$ (Qiagen, Courtaboeuf, France) in TSE buffer containing in millimolar: 25 Tris- $\mathrm{HCl} \mathrm{pH} \mathrm{8.0,75}$ $\mathrm{NaCl}, 25$ EDTA pH 8.0 and SDS 1\% (SigmaAldrich, Saint Quentin, France). DNA fragments were precipitated with isopropanol and washed with $70 \%$ ethanol prior to being dissolved in $100 \mu \mathrm{l}$ of distilled water. DNA was amplified in two sets of reactions, one for each allele by PCR. The staggerer allele primers were: 5'-CGTTTGGCAAACTCCACC-3' and 5'-GATTGAAAGCTGACTCGTTCC-3'. The WT allele primers were: 5'-TCTCCCTTCTCAGTCCTGACA-3' and 5'-TATATTCCACCACACGGCAA-3'. The amplified fragments (318 bp Rora ${ }^{+}$and $450 \mathrm{bp}$ Rora $^{\mathrm{sg}}$ ) were detected by electrophoresis on a $2 \%$ agarose gel.

Gonadectomy and hormone replacement therapy

WT animals were bilaterally gonadectomised at 4 weeks of age under avertin anaesthesia $(0.024$ cc/g i.p.) and kept until 9, 13, 18 or 24 months, when blood was collected for sex steroid analysis and brains dissected for cell counts. All gonadectomised mice had steroids levels below detection limits.

Twenty-four hours after gonadectomy, animals received subcutaneous 90-day time-release hormone pellets (Innovative Research of America, FL. USA) releasing either $17 \beta$-estradiol (1,3,5-estratriene3,17 $\beta$-diol; $8.0 \mu \mathrm{g} /$ day), progesterone (4-pregnene3,20-dione, $0.38 \mathrm{mg} /$ day) or vehicle. In addition, gonadectomised males were treated with dihydrotestosterone ( $5 \alpha$-androstan-17 $\beta$-ol-3-one, $0.14 \mathrm{mg} /$ day) which cannot be converted to $17 \beta$-estradiol by aromatase. Hormone pellets were replaced under short isoflurane anaesthesia $\left(3.5 \%\right.$ isoflurane; $\left.0.5 \% \mathrm{O}_{2}\right)$, four times over 1 year of treatment. Blood was collected every 3 months early in the light cycle (2$3 \mathrm{~h}$ after lights-on) to measure steroid concentrations by radioimmunoassay (RIA; Diagnostic Systems Laboratories, Inc., USA).

Body weight of different experimental groups was monitored on a regular basis. Initial group sizes of intact and castrated mice ranged from five to ten but were reduced to only two to five mice at 18 and 24 months due to a high incidence of late onset mortality. In the hormone replacement therapy experiment, initial group sizes ranged from five to eight animals. 
Blood and brain collection for analysis of steroid levels

Blood samples were collected 2-3 h after lights-on, centrifuged at $3,000 \times \mathrm{g}$ for $10 \mathrm{~min}$ at $4^{\circ} \mathrm{C}$, and the plasma stored at $-80^{\circ} \mathrm{C}$ until subsequent analysis. For brain steroids, animals were sacrificed by rapid cervical dislocation at 3,9 and 13 months of age. The cerebellum was quickly removed on ice and stored at $-80^{\circ} \mathrm{C}$ until steroid analysis

\section{Measurement of steroid concentrations}

Steroid analysis was carried out on individual plasma/ cerebellar samples according to a previously described method (Liere et al. 2000; Weill-Engerer et al. 2002; Liere et al. 2004).

Briefly, 60-68-mg cerebellum and $150-300-\mu$ plasma were used. Steroids were extracted from each sample with ten volumes of methanol together with the appropriate internal standards (Steraloids) added for steroid quantification: in plasma samples, ${ }^{2} \mathrm{H}_{5}$-testosterone (2 ng) for testosterone; ${ }^{2} \mathrm{H}_{5}$-17 $\beta$-estradiol (2 ng) for $17 \beta$-estradiol and 19-nor-progesterone (2 ng) for progesterone; in cerebellar samples, $5 \beta$-androstane$3 \beta$-ol-17-one (1 ng) for pregnenolone and $5 \alpha$ pregnane-3 $\alpha$-ol-20-one (allopregnanolone), and ${ }^{2} \mathrm{H}_{6}$ $5 \alpha$-pregnane-3,20-dione, ${ }^{2} \mathrm{H}_{6}-5 \alpha$ dihydroprogesterone (2 ng) for $5 \alpha$-dihydroprogesterone. Pregnenolone, progesterone and allopregnanolone were kind gifts from Roussel-Uclaf (Romainville, France), $5 \alpha$ dihydroprogesterone, $5 \beta$-androstane- $3 \beta$-ol-17-one and estradiol were purchased from Sigma. The unconjugated steroids were purified and isolated by solid phase extraction (SPE) on C18 silica minicolumns (International Sorbent technology, Mid Glamorgan, UK) with $5 \mathrm{ml} \mathrm{MeOH} / \mathrm{H}_{2} \mathrm{O}(90 / 10, v / v)$ with the recycling procedure (Liere et al. 2004). They were filtered and submitted to high-performance liquid chromatography (HPLC) coupled to a 202 model Gilson fraction collector. HPLC was achieved with a Lichrosorb Diol column $(25 \mathrm{~cm} \times 4.6 \mathrm{~mm}, 5 \mu \mathrm{m})$ and the solvent system consisted of hexane and mixture A $(90: 10, v / v)$, the latter composed of hexane-isopropanol $(85: 15, v / v)$. The elution was performed at a flow rate of $1 \mathrm{ml} / \mathrm{min}$ at $30^{\circ} \mathrm{C}$. Fraction I containing $5 \alpha$-dihydroprogesterone and ${ }^{2} \mathrm{H}_{6}-5 \alpha$-dihydroprogesterone was collected between 3 and $11 \mathrm{~min}$. Fraction II containing pregnenolone, progesterone, testosterone and $17 \beta$-estradiol and corresponding internal standards was collected from 10 to $30 \mathrm{~min}$. The fraction II was derivatized with heptafluorobutyric anhydride (Pierce Chemical CA., Rockford, IL, USA), and the fraction I with N-methylN-trimethylsilyl-trifluoroacetamide/ammonium iodure/ dithioerythritol, before identification and quantification by gas chromatography-mass spectrometry (GC-MS). GC injection was carried out in the splitless mode with a GC 8000 Top gas chromatograph (Carlo Erba) and the oven temperature was ramped up from $50^{\circ} \mathrm{C}$ to $330^{\circ} \mathrm{C}$ at $20^{\circ} \mathrm{C} / \mathrm{min}$. The mass spectrometer (model 150, Finnigan Automass, Argenteuil, France) was operated in the electron impact mode with ionisation energy of $70 \mathrm{eV}$ in single ion monitoring mode. Identification of derivatized steroids was performed according to the GC retention time and ratio between the signals of two diagnostic ions. Quantification was carried out according to the major diagnostic ion (quantification ion). Each GC-MS measurement of individual plasma or brain sample was made in duplicate. The detection limits for plasma progesterone, testosterone and $17 \beta$-estradiol were respectively $0.01,0.03$ and $0.01 \mathrm{ng} / \mathrm{ml}$. The detection limits for brain pregnenolone, progesterone, $5 \alpha$ dihydroprogesterone and allopregnanolone respectively $0.80,0.10,0.10$ and $0.20 \mathrm{ng} / \mathrm{g}$.

Histology and Purkinje cell quantitation

Under deep anaesthesia with $3.5 \%$ chloral-hydrate, mice were transcardially perfused with physiological saline and $4 \%$ paraformaldehyde in $0.1 \mathrm{M}$ sodium phosphate-buffered saline ( $\mathrm{pH}$ 7.4). Brains were dissected, post-fixed in $4 \%$ paraformaldehyde at $4{ }^{\circ} \mathrm{C}$ overnight, then dehydrated, cleared and embedded in paraffin. Serial sagittal brain sections of $8 \mu \mathrm{m}$ were stained with cresyl violet Nissl stain, which allows easy identification of the soma and nucleus of all Purkinje cells (Frederic et al. 1992).

Purkinje cells were counted on a Leica microscope (Leica Paris, France) in male and female mice aged 3, 9, 13, 18 and 24 months. Counts were made blind and verified by a second investigator. Purkinje cell profiles were determined in every 40th section of the whole cerebellum as previously described (Doulazmi et al. 1999). In each parasagittal section, the Purkinje cell layer was examined using an $\times 100$ objective $(\times 1000$ total magnification) and every Purkinje cell with a visible nucleus was counted. To 
estimate the total number of Purkinje cells in each animal, profile counts were multiplied by 40 and corrected by the Hendry correction factor (Hendry 1976). This method provides similar Purkinje cell numerical estimates as other stereological techniques (Zanjani et al. 1996; Fan et al. 2001; Zanjani et al. 2004) and permits direct comparison with previously published Purkinje cell counts of this mutant.

Statistical analysis

\section{Steroid concentrations}

In order to have a normal distribution of sex steroids concentrations, we logged the data and verified normality by the Kolmogorov-Smirnov Goodnessof-Fit test. In case of a log-normal distribution, the differences in testosterone, $17 \beta$-estradiol and progesterone concentrations were assessed by a two-way (genotype, age) analysis of variance (ANOVA) with post hoc comparisons by the Newman-Keuls test. Since progesterone concentrations in males were not normally distributed after log-transformation, we applied non parametric ANOVA (Kruskal-Wallis with Mann-Whitney post hoc tests). We used the Spearman's rank correlation test to study the correlation between log plasma steroid concentrations and Purkinje cell number. Data are presented as the mean \pm SEM. Significance was defined at $P \leq 0.05$.

\section{Cell counts}

The difference between mean Purkinje cell numbers during ageing was assessed by 2- or 3-way analysis of variance (ANOVA) with post-hoc Newman-Keuls test. Following castration and hormone treatment Purkinje cell numbers were compared by the Kruskal-Wallis test. Data are presented as the mean \pm SEM. Significance was defined at $P \leq 0.05$.

\section{Results}

Circulating sex steroids decrease with age in advance of Purkinje cell death

It is known that female mice have fewer Purkinje cells than males and that these neurons begin to die from 18 months in WT mice and much earlier in $\mathrm{Rora}^{+/ s g}$ mice (Doulazmi et al. 1999). To test the potential link between Purkinje cell death and circulating sex steroids, we measured plasma sex steroids between 3 and 24 months and correlated them with Purkinje cell numbers from the same animals. We analysed four to eight animals at each of five-age points for both genders in both genotypes.

We confirmed the gender difference in WT Purkinje cell numbers (Doulazmi et al. 1999), with WT males having 7\% more Purkinje cells than females $\left(F_{1,62}=17, P<0.0001\right.$; Fig. $1 \mathrm{a}$ and $\left.\mathrm{a}^{\prime}\right)$, and the loss of Purkinje cells from 18 months in WTs and much earlier $\left(F_{1,118}=145, P<0.0001\right)$ in $\mathrm{Rora}^{+/ \mathrm{sg}}$ mice (Fig. 2; Doulazmi et al. 1999). Because Purkinje cell death begins earlier in Rora $^{+/ s g}$ males (Fig. 1a and a'; Doulazmi et al. 1999), we observed that from 9 months of age Rora $^{+/ s g}$ males and females had the same number of Purkinje cells (compare Fig. 1a vs. a', Fig. 3).

Concerning sex steroids, in mice of both genotypes and genders plasma concentrations decreased with age $\left(17 \beta\right.$-estradiol $F_{4,85}=5, P<0.001$; progesterone $F_{4,85}=$ 20, $P<0.0001$; testosterone $F_{4,85}=2.6, P<0.05$ ). There was also an effect of genotype, with plasma concentrations being lower in Rora $^{+/ s g}$ animals (17 $\beta$-estradiol, $F_{1,85}=16, P<0.0001$; progesterone, $F_{1,85}=17, P<$ 0.0001 ; testosterone, $\left.F_{1,85}=12.6, P<0.001\right)$.

Additional analysis revealed that in WT mice progesterone $(P<0.01 ;$ Fig. $1 \mathrm{c})$ and $17 \beta$-estradiol $(P<0.05$; Fig 1 b) decreased in males from around 9 months, i.e. before Purkinje cell death (Fig. 1a). Also, testosterone fell from 18 months $(P<0.05)$ in parallel with Purkinje cell loss (Fig. 1d vs. a). In contrast, in WT females changes in plasma sex steroids with age were less evident consistent with our use of randomly cycled mice, in which large hormonal variations due to the estrus cycle will mask smaller changes with age (Nelson et al. 1981). However, progesterone decreased from 13 months $\left(P<0.01\right.$; Fig. $\left.1 c^{\prime}\right)$, while $17 \beta$-estradiol did not show clear variance with age (Fig. $\left.1 b^{\prime}\right)$ and testosterone was too low to detect any changes.

Correspondingly in $\mathrm{Rora}^{+/ s g}$ mice, plasma sex steroids also decreased either before or in parallel to the acceleration in Purkinje cell death at 9 months of age (Fig. 1). In males, progesterone and $17 \beta$-estradiol were reduced from 3 months $(P<0.05$ each; Fig. $1 \mathrm{~b}$ and c) so that they were less than WT $(P<0.001, P<$ 0.05 , respectively; Fig. $1 \mathrm{~b}, \mathrm{c})$. Also, testosterone 


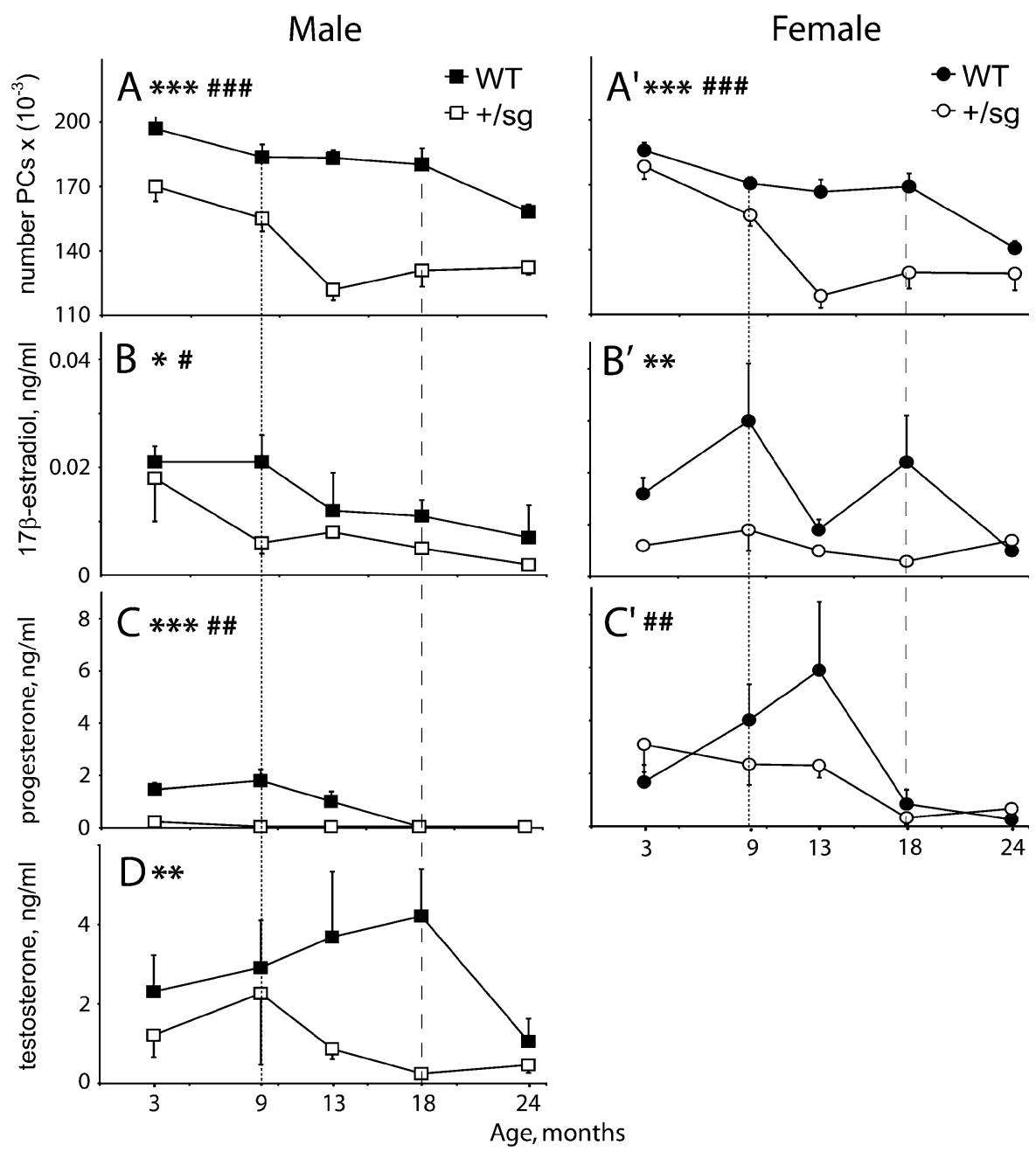

Fig. 1 Purkinje cell number and circulating sex steroids decrease with age. Evolution of Purkinje cell numbers (a and a') and circulating sex steroid concentrations $17 \beta$-estradiol (b and $\mathbf{b}^{\prime}$ ), progesterone (c and $\mathbf{c}^{\prime}$ ) and testosterone (d) in wild-type $(W T)$ and heterozygous staggerer $\left(\right.$ Rora $\left.^{+/ s g}\right)$ males (left panels) and females (right panels) from 3 to 24 months of age. Values are represented as mean \pm S.E.M; $n=4-8$. The ages when rapid

levels fell from 9 months, the time when Purkinje cell death accelerates (Fig. 1a vs 1d). In female Rora $^{+/ s g}$ mice, progesterone decreased with age $(P<0.01$ Fig. 1c'), 17ß-estradiol was less than in WT $(P<$ 0.01 ) even before Purkinje cells loss (Fig. 1a' vs $1 b^{\prime}$ ), and testosterone was almost undetectable.

In addition, these changes in plasma sex steroid concentrations correlated with Purkinje cell numbers of the same animals. Specifically, in males Purkinje cell numbers correlated directly with plasma $17 \beta-$
Purkinje cell death commences are indicated by vertical dashed $(W T)$ or dotted $\left(\right.$ Rora $\left.^{+/ s g}\right)$ lines. Significant differences WT vs. Rora $^{+/ s g}$ : single asterisk $P<0.05$; double asterisk $P<0.01$; triple asterisk $P<0.001$. Significant differences within genotypes: single number sign $P<0.05$; double number sign $P<$ 0.01 ; triple number sign $P<0.001$

estradiol, progesterone and testosterone concentration in both WT and $\mathrm{Rora}^{+/ s g}$ mice (17 $\beta$-estradiol, Spearman $\mathrm{Rho}=0.5, P<0.01$; progesterone, Rho= $0.63, P<0.01$; testosterone, Rho=0.46, $P<0.05)$. In females, Purkinje cell numbers correlated with $17 \beta$ estradiol (Spearman Rho $=0.36, P<0.05$ ) but not with progesterone concentrations, possibly because we used randomly cycled females.

In summary, in WT and Rora $^{+/ s g}$ animals circulating $17 \beta$-estradiol and progesterone were reduced in 


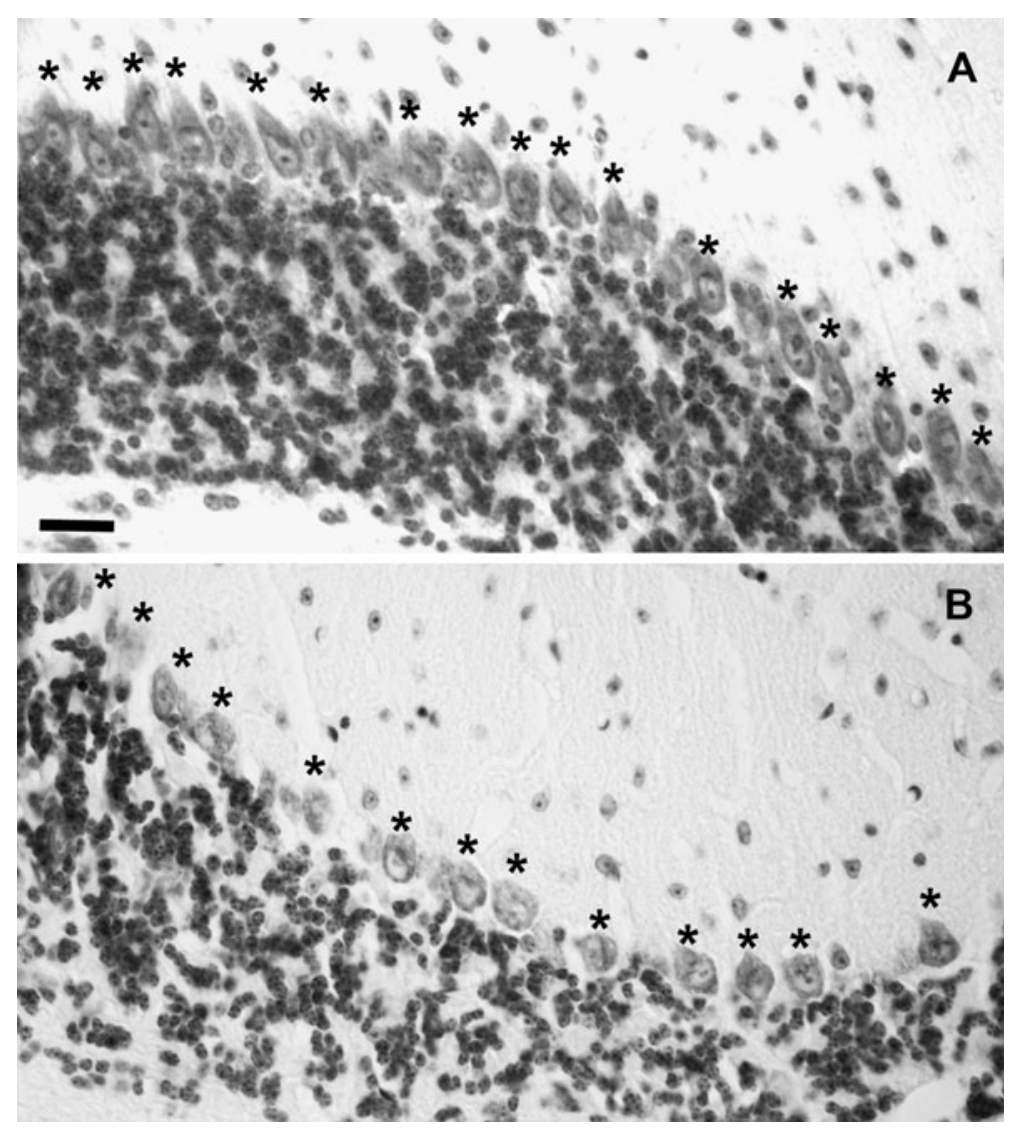

Fig. 2 Fewer Purkinje cells in the aged Rora $^{+/ s g}$ than WT cerebellum. Micrographs of cerebellum stained with cresyl violet showing the Purkinje cell layer of WT (a) and $\mathrm{Rora}^{+/ s g}$ (b) cerebella at 18 months of age. The density of the Purkinje cells (single asterisk) is less in the Rora ${ }^{+/ s g}$ tissue. Bar $=50 \mu \mathrm{m}$

survival did not take place (Litteria 1994), thus gonadectomised mice of both genders had the same number of Purkinje cells. Also gonadectomy advanced Purkinje cell loss, with both genders steadily losing Purkinje cells from 9 months of age $\left(F_{3,79}=11\right.$ $P<0.0001$; Fig. 3). Thus, because Purkinje cells do not start to die in intact WT mice until 18 months, gonadectomised WT males had significantly fewer Purkinje cells than intact males at $13(-9 \%)$ and 18 $(-18 \%)$ months $(P<0.05$, Fig. 3). However in gonadectomised females, the advanced Purkinje cell death ( 9 vs. 18 months; $P<0.05$ ), commenced from the number of Purkinje cells usually found in males, so that overall the number of Purkinje cells did not become significantly less than in intact females (Fig. 3).

To explore the relation of individual sex steroids to the advanced Purkinje cell loss in gonadectomised animals, we tested the effect of individual hormone mental sexually dimorphic changes in neuronal 


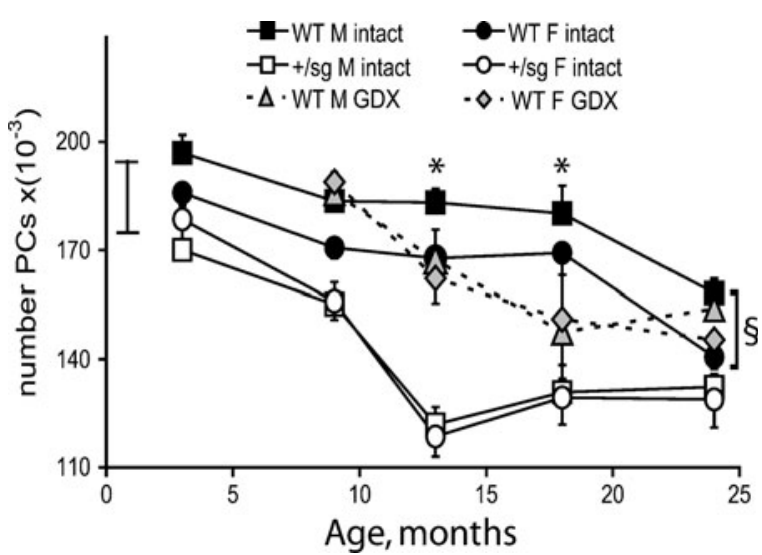

Fig. 3 Hormone deficiency advances Purkinje cell loss. Mean ( \pm S.E.M) number of Purkinje cells $(P C)$ of intact and gonadectomized $(G D X)$ WT and Rora $^{+/ s g}$ mice from 3 to 24 months. In WT mice, PC death begins earlier in gonadectomised $(G D X)$ than intact mice. Also GDX removes the sexual dimorphism of PC numbers (Litteria 1994) so that GDX males and females have the same numbers of PCs. In Rora $^{+/ s g}$ mice in association with their endocrine deficiency there is also no sexual dimorphism in the number of Rora $^{+/ s g}$ PCs, which have already begun to die by 3 months of age and whose death accelerates from 9 months of age. $\mathbf{I}=$ range of $\mathrm{PC}$ number in males at 1 month (Doulazmi et al. 1999). Significant differences intact vs. GDX: single asterisk $P<0.05$. Significant differences WT male vs. female: section sign $P<0.0001$

replacement therapy for 12 months to normalise circulating sex steroids. Plasma $17 \beta$-estradiol, progesterone and dihydrotestosterone were monitored every 3 months and were in the physiological range (data not shown). However for both genders, at 13 months of age there were no apparent differences in Purkinje cell number between gonadectomised mice with or without replacement of individual hormones, $17 \beta$-estradiol, progesterone or dihydrotestosterone for 1 year (Fig. 4).

In summary, in ageing WT animals Purkinje cell death is advanced after long-term deficiency of sex steroids, although replacement of individual hormones could not reverse this premature cell loss.

Cerebellar neurosteroid concentrations do not change with age

Our data indicate a relation between circulating sex steroids and Purkinje cell survival, with neuronal loss being preceded by falling $17 \beta$-estradiol and progesterone and precipitated by long-term hormone deficiency.
However there is a delay between falling steroid levels and Purkinje cell loss, which may be due to the neuroprotective properties of Purkinje cell-synthesised neurosteroids. Therefore, we measured cerebellar neurosteroids before and during Purkinje cell death in WT and Rora $^{+/ s g}$ mice ( $n=6$ for each gender and genotype).

In WT animals, cerebellar neurosteroids did not vary between 3 and 13 months of age (Fig. 5). However, at all ages there was a gender difference with lower neurosteroid (pregnenolone, $5 \alpha$-dihydroprogesterone and allopregnanolone) concentrations in females compared to males $\left(F_{1,28}=36 P<0.0001 ; F_{1,29}=26 P<0.0001\right.$; $F_{1,29}=29 P<0.0001$, respectively; compare Fig. 5 left and right columns). These data parallel the stable number of Purkinje cells between 3 and 13 months and smaller number of Purkinje cells in the female cerebellum (Figs. 1 and 3; Doulazmi et al. 1999).

In addition, in $\mathrm{Rora}^{+/ s g}$ mutant mice cerebellar steroids also did not change between 3 and 13 months (Fig. 5). Furthermore in contrast to WT, cerebellar steroid concentrations were the same in male and female $\mathrm{Rora}^{+/ \mathrm{sg}}$ mice (Fig. 5, compare left and right columns). As a consequence, compared to WT cerebellar neurosteroids were reduced in $\mathrm{Rora}^{+/ s g}$ males (pregnenolone $F_{1,29}=13 \quad P<0.001,5 \alpha$-dihydroprogesterone $F_{1,29}=4 \quad P<0.05$, allopregnanolone $F_{1,29}=15$

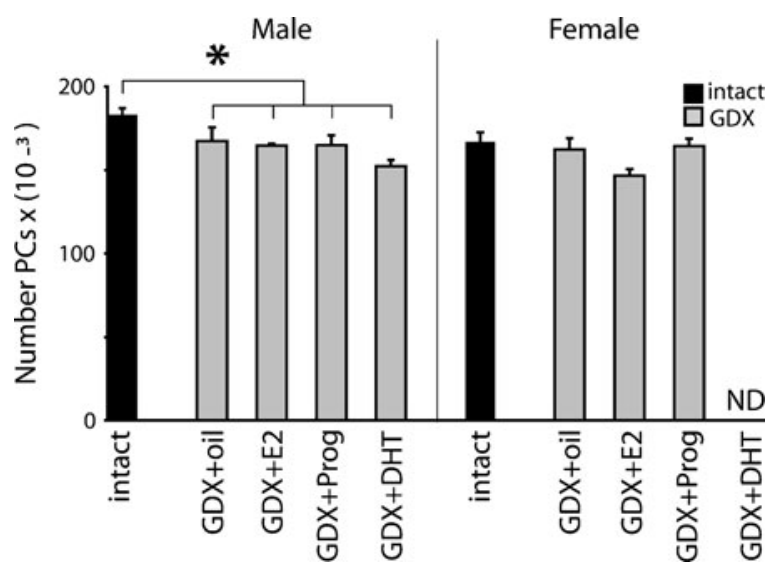

Fig. 4 No effect of hormone treatment on Purkinje cell death. Mean $( \pm$ S.E.M) number of Purkinje cells of 13-month old intact or gonadectomized (GDX) WT animals treated for 12 months with placebo (GDX-oil), 17ß-estradiol $(+E 2)$, progesterone $(+$ Prog) or dihydrotestosterone $(D H T)$. GDX WT males had fewer PCs than intact WT. There were no significant differences in PC number between the different hormone treatment groups of gonadectomized males and females. Significant differences intact vs. GDX: single asterisk $P<0.05$ 

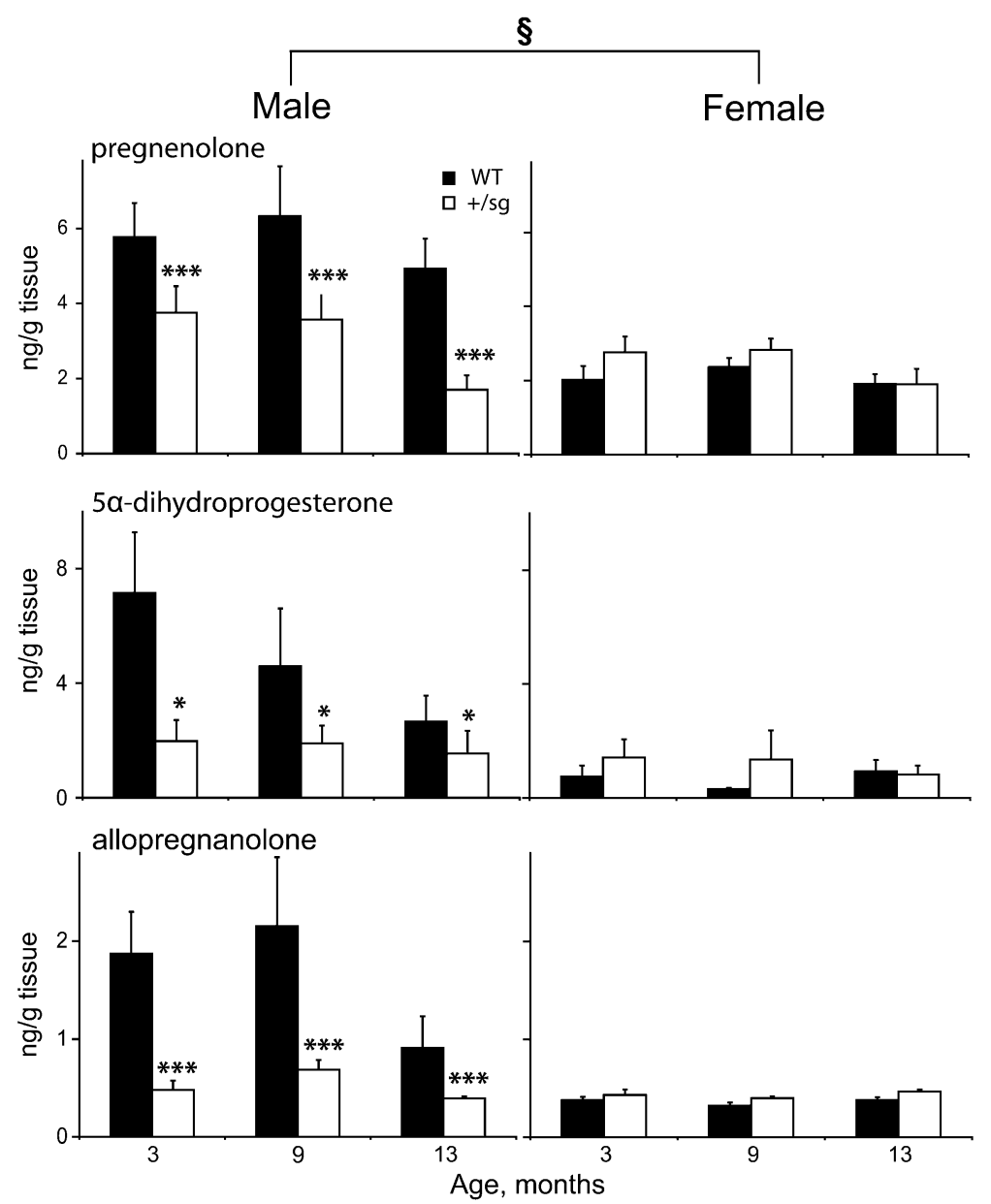

Fig. 5 Cerebellar neurosteroids do not decrease with age. Concentrations (mean \pm S.E.M) of cerebellar neurosteroids, pregnenolone, allopregnanolone and $5 \alpha$-dihydroprogesterone in 3-13-month-old wild-type (WT) and $\mathrm{Rora}^{+/ s g}$ mice ( $n=6$ per group). In WT, these neurosteroid concentrations are higher in males than females and in

$P<0.001)$. Thus in contrast to WT, in Rora $^{+/ s g}$ mice there is no correlation between stable neurosteroid concentrations and falling numbers of Purkinje cells.

In summary, cerebellar neurosteroid concentrations do not change between 3 and 13 months, and, although they are reduced in $\mathrm{Rora}^{+/ \mathrm{sg}}$ males, their profile does not accord with ongoing Purkinje cell loss in the $\mathrm{Rora}^{+/ s g}$ cerebellum.

\section{Discussion}

In this study, we examined the relation between agerelated neuronal degeneration and sex steroids during normal ageing, and in Rora $^{+/ s g}$ and gonadectomised
$\mathrm{ROR}^{+/ \mathrm{sg}}$ the sexual dimorphism disappears, with reduced neurosteroid concentrations in males. Significant differences WT vs. Rora $^{+/ s g}$ : single asterisk $P<0.05$; triple asterisk $P<0.001$. Significant differences WT male vs. female: section sign $P<0.05$

experimental models. Our data reveal a statistical correlation between age, Purkinje cell loss and falling levels of circulating sex steroids, and a deficit in both circulating sex steroids and cerebellar neurosteroids in $\mathrm{Rora}^{+/ s g}$ mice. From these data, we propose that during ageing Purkinje cell death is sex steroid dependent and that the precocious neuronal loss in Rora $^{+/ s g}$ animals results from premature sex steroid deficiency.

Death of ageing Purkinje cells is related to decreased sex steroids

From the results from this study, we hypothesise that a deficiency of circulating sex steroids causes agerelated Purkinje cell death. Our study provides three 
independent lines of evidence to support this hypothesis. First, in normal ageing animals circulating steroids fall just in advance of, or in parallel to, Purkinje cell death. Importantly, throughout the ageing process the number of surviving Purkinje cells directly correlates with plasma sex steroid concentrations (17 $\beta$-estradiol, progesterone and testosterone in males and $17 \beta$-estradiol in females). Second, when circulating sex steroids are removed prematurely by gonadectomy, the onset of Purkinje cell death is advanced from 18 to 9 months. This finding is consistent with the known neuroprotective function of sex steroids in development (Tsutsui 2008; Biamonte et al. 2009), injury (De Nicola et al. 2009; Fargo et al. 2009; Herson et al. 2009; Suzuki et al. 2009) and neurodegenerative disease (Bourque et al. 2009; Garcia-Segura and Balthazart 2009; Gold and Voskuhl 2009) and adds that they have a similar neuroprotective role during normal ageing. Third, when Purkinje cell death is advanced in a genetic model of premature ageing $\left(\right.$ Rora $^{+/ s g}$ mice; Jarvis et al. 2002; Boukhtouche et al. 2006a) we identify, for the first time, that circulating sex steroid concentrations are prematurely reduced and that this sex steroid loss precedes, or is concurrent with, Purkinje cell death. Thus plasma sex steroid concentrations and Purkinje cell numbers remain concordant during ageing in both normal WT and Rora $^{+/ s g}$ mutant mice; data which concur with sex steroid deficiency in disorders involving neuronal loss, such as Alzheimer's disease (Schumacher et al. 2003; Pike et al. 2009). Although the temporal correlation of Purkinje cell loss and falling steroid concentrations during ageing could be just circumstantial, our data showing similar but premature Purkinje cell loss in two different models of endocrine deficiency (gonadectomy or $\mathrm{Rora}^{+/ s g}$ mutation) implies a causal relationship.

We further probed the relation between the requirement for circulating sex steroids and survival of ageing Purkinje cells by testing whether hormone replacement treatment prevented premature Purkinje neuron loss following gonadectomy. Although our treatment did not improve Purkinje cell survival, we only gave monotherapy and mice normally have circulating levels of all three hormones: $17 \beta$-estradiol, progesterone and testosterone. Indeed, consistent with our data, it has recently been shown that dihydrotestosterone replacement in orchidectomised rats does not increase brain steroid concentrations (Pluchino et al. 2008), and that effective neuroprotection requires the combination of exogenous oestrogens and progestins (Smith et al. 1987; Kipp and Beyer 2009; Lenzi et al. 2009). Therefore the failure of individual sex steroids to prevent premature Purkinje cell death post-gonadectomy, further supports the hypothesis that survival of ageing Purkinje cells requires the integrity of the whole circulating sex steroid profile.

Cerebellar neurosteroids do not decrease with age

Although our data reveal a clear relation between agerelated Purkinje cell death and circulating sex steroids, Purkinje cells also synthesise neurosteroids (Baulieu 1997; Tsutsui et al. 2003), for which changes during normal ageing remain ill-defined (Schumacher et al. 2003; Rosario et al. 2009) and which could explain the delay between falling plasma steroids and age-related Purkinje cell death.

We show that cerebellar neurosteroids do not change between young adult (3 months) and aged (13 months) animals. We also show that cerebellar neurosteroid synthesis is sexually dimorphic in WTs (being higher in males) but not in ora $^{+/ s g}$, so that $\mathrm{Rora}^{+/ s g}$ males have reduced cerebellar neurosteroids compared to age-matched controls, even as young adults (i.e. at 3 months). Given that progestins are neuroprotective (Garcia-Segura and Balthazart 2009; Herson et al. 2009), the expression profile we observed is consistent with the stable, sexually dimorphic number of WT Purkinje cells (this study; Doulazmi et al. 1999) as well as compromised survival of young adult male Rora $^{+/ s g}$ Purkinje cells. However, we did not observe a significant decrease in neurosteroid concentrations in Rora $^{+/ s g}$ females, despite their accelerating age-related Purkinje cell loss from 9 months. This is consistent with human studies showing age-related decrease of brain sex steroids in males but not in females (Rosario et al. 2009) and the sexually dimorphic expression of key neurosteroidogenic enzymes, such as StAR, P450scc and aromatase (Lavaque et al. 2006). Taken together, our data do not demonstrate a clear role for cerebellar neurosteroids in the survival or death of ageing Purkinje cells.

Death of ageing Purkinje cells: interactions of sex steroids and $\mathrm{ROR} \alpha$

Although sex steroids are protective to immature Purkinje cells (Tsutsui 2008; Biamonte et al. 2009), 
our data from hormone deficient mice $\left(\mathrm{Rora}^{+/ s g}\right.$ and gonadectomised WT) now add that sex steroids also have an important neuroprotective role during normal ageing. In these $\mathrm{Rora}^{+/ s g}$ and gonadectomised WT animals the number of Purkinje cells only declined from 9 months of age (Fig. 3); i.e. hormone deprived Purkinje cells continue to survive until the animals are aged (i.e. to 9 months), thus revealing that vulnerability to sex steroid deficiency is a phenomenon of the ageing Purkinje cell rather than young adult neurons which survive regardless.

A re-development of hormone dependency as Purkinje cells age is entirely consistent with physiological changes which take place during ageing and the functions of sex steroids. As the brain ages, among other alterations that may adversely affect neuronal survival, neurotrophic factor synthesis/signalling decreases (Bishop et al. 2010; Katoh-Semba et al. 1998; Sonntag et al. 1999; Tapia-Arancibia et al. 2008; Luppi et al. 2009) and oxidative stress and free radicals accumulate (Hanawalt 2008). Importantly for age-related Purkinje cell death, sex steroids regulate both these processes. First, sex steroids promote the expression and signalling of brain-derived neurotrophic factor (BDNF; Begliuomini et al. 2007; Kaur et al. 2007) and insulin-like growth factor-1 (IGF-1; Garcia-Segura et al. 2006; Alonso et al. 2008; Luppi et al. 2009), both of which are survival factors for Purkinje cells (Larkfors et al. 1996; Lindholm et al. 1997; Fukudome et al. 2003). Indeed the neuroprotective action of oestrogen and progesterone are mediated through BDNF and IGF-1 receptor signalling and their downstream pathways through MAP kinase and phosphatidylinositol-3 kinase (GarciaSegura et al. 2006; Kaur et al. 2007; Alonso et al. 2008). Second, sex steroids protect against oxidative stress and free radicals (Dubal et al. 1999; Ardeshiri et al. 2006; Kelley et al. 2008; Jung et al. 2010), processes to which Purkinje cells are known to be sensitive (Horn and Schlote 1992; Brasko et al. 1995; Fonnum and Lock 2000). Therefore in WT mice, falling circulating sex steroid concentrations during ageing (this study; Smith et al. 2005) and long-term hormone insufficiency post-gonadectomy, can adversely affect Purkinje cells by simultaneously reducing two key survival factors and protection against oxidative stress; a combination which only becomes critical as free radicals and oxidative stress accumulate with age (Hanawalt 2008).
This hypothesis linking the decrease in circulating sex steroids with death of ageing Purkinje cells is reinforced in $\mathrm{Rora}^{+/ s g}$ mice. In these mice, we show that circulating sex steroids fall prematurely, consistent with the role of $\operatorname{ROR} \alpha$ regulating enzymes involved in steroidogenesis, e.g. 3ß-hydroxysteroid dehydrogenases (Kang et al. 2007) and aromatase (Odawara et al. 2009). In addition Rora $^{+/ s g}$ Purkinje cells, which are already intrinsically vulnerable due to their genetic defect (Herrup and Mullen 1981) and gradually degenerate from 1 month of age (Doulazmi et al. 1999), die early (as demonstrated by accelerated Purkinje cell loss in Rora $^{+/ s g}$ from 9 months). However, the fact that Purkinje cell loss was only gradual to 9 months confirms that Purkinje cell susceptibility to circulating sex steroid deficiency is a phenomenon of ageing; i.e. even though genetically vulnerable Purkinje cells gradually die, it is only after circulating sex steroids fail prematurely and Purkinje cells become aged that their death accelerates. Given that ROR $\alpha$ itself promotes BDNF synthesis (Qiu et al. 2007), IGF-1 signalling (Jaradat et al. 2006) and anti-oxidant function (Boukhtouche et al. 2006b), Ror $\alpha$ haplo-insufficiency in the Rora $^{+/ s g}$ mouse renders their Purkinje cells more vulnerable to oxidative stress that accrues during ageing. This effect would be exacerbated by the premature loss of neurotrophic and anti-oxidant properties of sex steroids, initially endogenous neurosteroids (Sakamoto et al. 2001; Sasahara et al. 2007; Tsutsui 2008) then circulating hormones. Since in WT animals ROR $\alpha$ expression does not appear to vary with age (Sharman et al. 2007), we propose that the difference in Purkinje cell number between Rora $^{+/ s g}$ and gonadectomised WT after 9 months of age reflects the added vulnerability induced by Ror $\alpha$ haplo-insufficiency on top of susceptibility of ageing Purkinje cells to sex steroid deficiency.

\section{Conclusions}

In conclusion, this study reveals that age-related cerebellar Purkinje cell neurodegeneration correlates with the decline in circulating sex steroids in both WT and $\mathrm{Rora}^{+/ s g}$ mice. In contrast, cerebellar neurosteroids do not decrease with age, but are decreased in male $\mathrm{Rora}^{+/ s g}$ which might cause or enhance the vulnerability of their mutant Purkinje cells. From these data, we hypothesise that during normal ageing, 
death of Purkinje cells can be delayed by the combination of circulating sex steroids or advanced by premature sex steroid loss, such may be induced by gonadal failure or Ror $\alpha$ haplo-insufficiency.

Acknowledgements We thank P. Bouquet and C. Nantet for help with the histology and A Cambourg for invaluable assistance with sample preparation for GC-MS steroid analysis. SJ is a recipient of a fellowship from the Prins Bernard Cultuur Fonds and the association 'Connaître les Syndromes Cérébelleux'. This work was supported by grants from GIS Institut de la Longévité GISL0403 A04026LS (to JM), AMA04003LSA (to YA) and le Ministère de la Recherche, France. We also thank Prof AJ Bower for his helpful comments on this manuscript.

Open Access This article is distributed under the terms of the Creative Commons Attribution Noncommercial License which permits any noncommercial use, distribution, and reproduction in any medium, provided the original author(s) and source are credited.

\section{References}

Alonso A, Moreno M, Ordonez P, Fernandez R, Perez C, Diaz F, Navarro A, Tolivia J, Gonzalez C (2008) Chronic estradiol treatment improves brain homeostasis during aging in female rats. Endocrinology 149:57-72

Andersen BB, Gundersen HJ, Pakkenberg B (2003) Aging of the human cerebellum: a stereological study. J Comp Neurol 466:356-365

Ardeshiri A, Kelley MH, Korner IP, Hurn PD, Herson PS (2006) Mechanism of progesterone neuroprotection of rat cerebellar Purkinje cells following oxygen-glucose deprivation. Eur J Neurosci 24:2567-2574

Azcoitia I, Sierra A, Veiga S, Garcia-Segura LM (2005) Brain steroidogenesis: emerging therapeutic strategies to prevent neurodegeneration. J Neural Transm 112:171-176

Baulieu EE (1997) Neurosteroids: of the nervous system, by the nervous system, for the nervous system. Recent Prog Horm Res 52:1-32

Begliuomini S, Casarosa E, Pluchino N, Lenzi E, Centofanti M, Freschi L, Pieri M, Genazzani AD, Luisi S, Genazzani AR (2007) Influence of endogenous and exogenous sex hormones on plasma brain-derived neurotrophic factor. Hum Reprod 22:995-1002

Biamonte F, Assenza G, Marino R, D'Amelio M, Panteri R, Caruso D, Scurati S, Yague JG, Garcia-Segura LM, Cesa R, Strata P, Melcangi RC, Keller F (2009) Interactions between neuroactive steroids and reelin haploinsufficiency in Purkinje cell survival. Neurobiol Dis 36:103-115

Bishop NA, Lu T, Yankner BA (2010) Neural mechanisms of ageing and cognitive decline. Nature 464:529-535

Boukhtouche F, Doulazmi M, Frederic F, Dusart I, Brugg B, Mariani J (2006a) RORalpha, a pivotal nuclear receptor for Purkinje neuron survival and differentiation: from development to ageing. Cerebellum 5:97-104

Boukhtouche F, Vodjdani G, Jarvis CI, Bakouche J, Staels B, Mallet J, Mariani J, Lemaigre-Dubreuil Y, Brugg B (2006b) Human retinoic acid receptor-related orphan receptor alpha1 overexpression protects neurones against oxidative stress-induced apoptosis. J Neurochem 96:17781789

Bourque M, Dluzen DE, Di Paolo T (2009) Neuroprotective actions of sex steroids in Parkinson's disease. Front Neuroendocrinol 30:142-157

Brasko J, Rai P, Sabol MK, Patrikios P, Ross DT (1995) The AMPA antagonist NBQX provides partial protection of rat cerebellar Purkinje cells after cardiac arrest and resuscitation. Brain Res 699:133-138

Caston J, Delhaye-Bouchaud N, Mariani J (1995) Motor behavior of heterozygous staggerer mutant $(+/ \mathrm{sg})$ versus normal $(+/+)$ mice during aging. Behav Brain Res 72:97102

Caston J, Hilber P, Chianale C, Mariani J (2003) Effect of training on motor abilities of heterozygous staggerer mutant $(\operatorname{Rora}(+) / \operatorname{Rora}(\mathrm{sg}))$ mice during aging. Behav Brain Res 141:35-42

Caston J, Chianale C, Mariani J (2004) Spatial memory of heterozygous staggerer $(\operatorname{Rora}(+) / \operatorname{Rora}(\mathrm{sg}))$ versus normal $(\operatorname{Rora}(+) / \operatorname{Rora}(+))$ mice during aging. Behav Genet 34:319-324

De Nicola AF, Labombarda F, Deniselle MC, Gonzalez SL, Garay L, Meyer M, Gargiulo G, Guennoun R, Schumacher M (2009) Progesterone neuroprotection in traumatic CNS injury and motoneuron degeneration. Front Neuroendocrinol 30:173-187

Doulazmi M, Frederic F, Lemaigre-Dubreuil Y, Hadj-Sahraoui N, Delhaye-Bouchaud N, Mariani J (1999) Cerebellar Purkinje cell loss during life span of the heterozygous staggerer mouse $(\operatorname{Rora}(+) / \operatorname{Rora}(\mathrm{sg}))$ is gender-related. J Comp Neurol 411:267-273

Dubal DB, Wilson ME, Wise PM (1999) Estradiol: a protective and trophic factor in the brain. J Alzheimers Dis 1:265274

Fan H, Favero M, Vogel MW (2001) Elimination of Bax expression in mice increases cerebellar purkinje cell numbers but not the number of granule cells. J Comp Neurol 436:82-91

Fargo KN, Foecking EM, Jones KJ, Sengelaub DR (2009) Neuroprotective actions of androgens on motoneurons. Front Neuroendocrinol 30:130-141

Feron C, Baudoin C (1992) Reduced influence of penile disability on the mating capacity of male staggerer mice. Reprod Nutr Dev 32:409-413

Fonnum F, Lock EA (2000) Cerebellum as a target for toxic substances. Toxicol Lett 112-113:9-16

Frederic F, Hainaut F, Thomasset M, Guenet JL, Delhaye-Bouchaud N, Mariani J (1992) Cell counts of Purkinje and inferior olivary neurons in the 'hyperspiny Purkinje cells' mutant mouse. Eur J Neurosci 4:127-135

Fukudome Y, Tabata T, Miyoshi T, Haruki S, Araishi K, Sawada S, Kano M (2003) Insulin-like growth factor-I as a promoting factor for cerebellar Purkinje cell development. Eur J Neurosci 17:2006-2016

Garcia-Segura LM, Balthazart J (2009) Steroids and neuroprotection: new advances. Front Neuroendocrinol 30:v-ix

Zanjani HS, Vogel MW, Delhaye-Bouchaud N, Martinou JC, Mariani J (1996) Increased cerebellar Purkinje cell numbers in mice overexpressing a human bcl-2 transgene. J Comp Neurol 374:332-341 
Garcia-Segura LM, Sanz A, Mendez P (2006) Cross-talk between IGF-I and estradiol in the brain: focus on neuroprotection. Neuroendocrinology 84:275-279

Gautheron V, Auffret A, Mattson MP, Mariani J, Vernet-der Garabedian B (2009) A new and simple approach for genotyping Alzheimer's disease presenilin-1 mutant knock-in mice. J Neurosci Meth 181:235-240

Gold SM, Voskuhl RR (2009) Estrogen and testosterone therapies in multiple sclerosis. Prog Brain Res 175:239251

Guastavino JM, Larsson K (1992) The staggerer gene curtails the reproductive life span of females. Behav Genet 22:101-112

Hadj-Sahraoui N, Frederic F, Zanjani H, Delhaye-Bouchaud N, Herrup K, Mariani J (2001) Progressive atrophy of cerebellar Purkinje cell dendrites during aging of the heterozygous staggerer mouse (Rora $(+/ \mathrm{sg})$ ) Brain Res. Dev Brain Res 126:201-209

Hamilton BA, Frankel WN, Kerrebrock AW, Hawkins TL, FitzHugh W, Kusumi K, Russell LB, Mueller KL, van Berkel V, Birren BW, Kruglyak L, Lander ES (1996) Disruption of the nuclear hormone receptor RORalpha in staggerer mice. Nature 379:736-739

Hanawalt PC (2008) Emerging links between premature ageing and defective DNA repair. Mech Ageing Dev 129:503-505

Hendry IA (1976) A method to correct adequately for the change in neuronal size when estimating neuronal numbers after nerve growth factor treatment. J Neurocytol 5:337-349

Herrup K, Mullen RJ (1981) Role of the Staggerer gene in determining Purkinje cell number in the cerebellar cortex of mouse chimeras. Brain Res 227:475-485

Herson PS, Koerner IP, Hurn PD (2009) Sex, sex steroids, and brain injury. Semin Reprod Med 27:229-239

Horn M, Schlote W (1992) Delayed neuronal death and delayed neuronal recovery in the human brain following global ischemia. Acta Neuropathol 85:79-87

Jaradat M, Stapleton C, Tilley SL, Dixon D, Erikson CJ, McCaskill JG, Kang HS, Angers M, Liao G, Collins J, Grissom S, Jetten AM (2006) Modulatory role for retinoid-related orphan receptor alpha in allergen-induced lung inflammation. Am J Respir Crit Care Med 174:12991309

Jarvis CI, Staels B, Brugg B, Lemaigre-Dubreuil Y, Tedgui A, Mariani J (2002) Age-related phenotypes in the staggerer mouse expand the RORalpha nuclear receptor's role beyond the cerebellum. Mol Cell Endocrinol 186:1-5

Jung ME, Yang SH, Brun-Zinkernagel AM, Simpkins JW (2002) Estradiol protects against cerebellar damage and motor deficit in ethanol-withdrawn rats. Alcohol 26:83-93

Jung ME, Ju X, Simpkins JW, Metzger DB, Yan LJ, Wen Y (2010) Ethanol withdrawal acts as an age-specific stressor to activate cerebellar P38 kinase. Neurobiol Aging (in press)

Kang HS, Angers M, Beak JY, Wu X, Gimble JM, Wada T, Xie W, Collins JB, Grissom SF, Jetten AM (2007) Gene expression profiling reveals a regulatory role for ROR alpha and ROR gamma in phase I and phase II metabolism. Physiol Genomics 31:281-294

Katoh-Semba R, Semba R, Takeuchi IK, Kato K (1998) Agerelated changes in levels of brain-derived neurotrophic factor in selected brain regions of rats, normal mice and senescence-accelerated mice: a comparison to those of nerve growth factor and neurotrophin-3. Neurosci Res 31:227-234

Kaur P, Jodhka PK, Underwood WA, Bowles CA, de Fiebre NC, de Fiebre CM, Singh M (2007) Progesterone increases brain-derived neuroptrophic factor expression and protects against glutamate toxicity in a mitogenactivated protein kinase- and phosphoinositide-3 kinasedependent manner in cerebral cortical explants. J Neurosci Res 85:2441-2449

Kelley MH, Taguchi N, Ardeshiri A, Kuroiwa M, Hurn PD, Traystman RJ, Herson PS (2008) Ischemic insult to cerebellar Purkinje cells causes diminished GABAA receptor function and allopregnanolone neuroprotection is associated with GABAA receptor stabilization. J Neurochem 107:668-678

Kipp M, Beyer C (2009) Impact of sex steroids on neuroinflammatory processes and experimental multiple sclerosis. Front Neuroendocrinol 30:188-200

Larkfors L, Lindsay RM, Alderson RF (1996) Characterization of the responses of Purkinje cells to neurotrophin treatment. J Neurochem 66:1362-1373

Lavaque E, Mayen A, Azcoitia I, Tena-Sempere M, Garcia-Segura LM (2006) Sex differences, developmental changes, response to injury and cAMP regulation of the mRNA levels of steroidogenic acute regulatory protein, cytochrome $\mathrm{p} 450 \mathrm{scc}$, and aromatase in the olivocerebellar system. J Neurobiol 66:308-318

Lenzi E, Pluchino N, Begliuomini S, Casarosa E, Merlini S, Giannini A, Luisi M, Kumar N, Sitruk-Ware R, Genazzani AR (2009) Central modifications of allopregnanolone and beta-endorphin following subcutaneous administration of Nestorone. J Steroid Biochem Mol Biol 116:15-20

Liere P, Akwa Y, Weill-Engerer S, Eychenne B, Pianos A, Robel P, Sjovall J, Schumacher M, Baulieu EE (2000) Validation of an analytical procedure to measure trace amounts of neurosteroids in brain tissue by gas chromatography-mass spectrometry. J Chromatogr B Biomed Sci Appl 739:301-312

Liere P, Pianos A, Eychenne B, Cambourg A, Liu S, Griffiths W, Schumacher M, Sjovall J, Baulieu EE (2004) Novel lipoidal derivatives of pregnenolone and dehydroepiandrosterone and absence of their sulfated counterparts in rodent brain. J Lipid Res 45:2287-2302

Lindholm D, Hamner S, Zirrgiebel U (1997) Neurotrophins and cerebellar development. Perspect Dev Neurobiol 5:83-94

Litteria M (1994) Long-term effects of neonatal ovariectomy on cerebellar development in the rat: a histological and morphometric study. Brain Res Dev Brain Res 81:113-120

Luppi C, Fioravanti M, Bertolini B, Inguscio M, Grugnetti A, Guerriero F, Rovelli C, Cantoni F, Guagnano P, Marazzi E, Rolfo E, Ghianda D, Levante D, Guerrini C, Bonacasa R, Solerte SB (2009) Growth factors decrease in subjects with mild to moderate Alzheimer's disease (AD): potential correction with dehydroepiandrosterone-sulphate (DHEAS). Arch Gerontol Geriatr 49(Suppl 1):173-184

Nelson JF, Felicio LS, Osterburg HH, Finch CE (1981) Altered profiles of estradiol and progesterone associated with prolonged estrous cycles and persistent vaginal cornification in aging C57BL/6 J mice. Biol Reprod 24:784-794 
Odawara H, Iwasaki T, Horiguchi J, Rokutanda N, Hirooka K, Miyazaki W, Koibuchi Y, Shimokawa N, Iino Y, Takeyoshi I, Koibuchi N (2009) Activation of aromatase expression by retinoic acid receptor-related orphan receptor (ROR) alpha in breast cancer cells: identification of a novel ROR response element. J Biol Chem 284:17711-17719

Pike CJ, Carroll JC, Rosario ER, Barron AM (2009) Protective actions of sex steroid hormones in Alzheimer's disease. Front Neuroendocrinol 30:239-258

Pluchino N, Ninni F, Casarosa E, Lenzi E, Begliuomini S, Cela V, Luisi S, Freschi L, Merlini S, Giannini A, Cubeddu A, Genazzani AR (2008) Sexually dimorphic effects of testosterone administration on brain allopregnanolone in gonadectomized rats. J Sex Med 5:2780-2792

Qin J, Suh JM, Kim BJ, Yu CT, Tanaka T, Kodama T, Tsai MJ, Tsai SY (2007) The expression pattern of nuclear receptors during cerebellar development. Dev Dyn 236:810-820

Qiu CH, Shimokawa N, Iwasaki T, Parhar IS, Koibuchi N (2007) Alteration of cerebellar neurotropin messenger ribonucleic acids and the lack of thyroid hormone receptor augmentation by staggerer-type retinoic acid receptor-related orphan receptor-alpha mutation. Endocrinology 148:1745-1753

Quackenbush LJ, Ngo H, Pentney RJ (1990) Evidence for nonrandom regression of dendrites of Purkinje neurons during aging. Neurobiol Aging 11:111-115

Rogers J, Silver MA, Shoemaker WJ, Bloom FE (1980) Senescent changes in a neurobiological model system: cerebellar Purkinje cell electrophysiology and correlative anatomy. Neurobiol Aging 1:3-11

Rogers J, Zornetzer SF, Bloom FE, Mervis RE (1984) Senescent microstructural changes in rat cerebellum. Brain Res 292:23-32

Rosario ER, Chang L, Head EH, Stanczyk FZ, Pike CJ (2009) Brain levels of sex steroid hormones in men and women during normal aging and in Alzheimer's disease. Neurobiol Aging. doi:10.1016/j.neurobiolaging.2009.04.008

Sakamoto H, Ukena K, Tsutsui K (2001) Effects of progesterone synthesized de novo in the developing Purkinje cell on its dendritic growth and synaptogenesis. J Neurosci 21:6221-6232

Sasahara K, Shikimi H, Haraguchi S, Sakamoto H, Honda S, Harada N, Tsutsui K (2007) Mode of action and functional significance of estrogen-inducing dendritic growth, spinogenesis, and synaptogenesis in the developing Purkinje cell. J Neurosci 27:7408-7417

Schumacher M, Weill-Engerer S, Liere P, Robert F, Franklin RJ, Garcia-Segura LM, Lambert JJ, Mayo W, Melcangi RC, Parducz A, Suter U, Carelli C, Baulieu EE, Akwa Y (2003) Steroid hormones and neurosteroids in normal and pathological aging of the nervous system. Prog Neurobiol 71:3-29

Sharman EH, Bondy SC, Sharman KG, Lahiri D, Cotman CW, Perreau VM (2007) Effects of melatonin and age on gene expression in mouse CNS using microarray analysis. Neurochem Int 50:336-344

Smith SS, Waterhouse BD, Woodward DJ (1987) Sex steroid effects on extrahypothalamic CNS. I. Estrogen augments neuronal responsiveness to iontophoretically applied glutamate in the cerebellum. Brain Res 422:40-51

Smith RG, Betancourt L, Sun Y (2005) Molecular endocrinology and physiology of the aging central nervous system. Endocr Rev 26:203-250

Sonntag WE, Lynch CD, Bennett SA, Khan AS, Thornton PL, Cooney PT, Ingram RL, McShane T, Brunso-Bechtold JK (1999) Alterations in insulin-like growth factor-1 gene and protein expression and type 1 insulin-like growth factor receptors in the brains of ageing rats. Neuroscience 88:269-279

Suzuki S, Brown CM, Wise PM (2009) Neuroprotective effects of estrogens following ischemic stroke. Front Neuroendocrinol 30:201-211

Tapia-Arancibia L, Aliaga E, Silhol M, Arancibia S (2008) New insights into brain BDNF function in normal aging and Alzheimer disease. Brain Res Rev 59:201-220

Thouvarecq R, Protais P, Jouen F, Caston J (2001) Influence of cholinergic system on motor learning during aging in mice. Behav Brain Res 118:209-218

Tsutsui K (2008) Progesterone biosynthesis and action in the developing neuron. Endocrinology 149:2757-2761

Tsutsui K, Sakamoto H, Ukena K (2003) A novel aspect of the cerebellum: biosynthesis of neurosteroids in the Purkinje cell. Cerebellum 2:215-222

Veiga S, Melcangi RC, DonCarlos LL, Garcia-Segura LM, Azcoitia I (2004) Sex hormones and brain aging. Exp Gerontol 39:1623-1631

Wada T, Kang HS, Angers M, Gong H, Bhatia S, Khadem S, Ren S, Ellis E, Strom SC, Jetten AM, Xie W (2008) Identification of oxysterol 7alpha-hydroxylase (Cyp7b1) as a novel retinoid-related orphan receptor alpha (RORalpha) (NR1F1) target gene and a functional cross-talk between RORalpha and liver X receptor (NR1H3). Mol Pharmacol 73:891-899

Weill-Engerer S, David JP, Sazdovitch V, Liere P, Eychenne B, Pianos A, Schumacher M, Delacourte A, Baulieu EE, Akwa $Y$ (2002) Neurosteroid quantification in human brain regions: comparison between Alzheimer's and nondemented patients. J Clin Endocrinol Metab 87:5138-5143

Woodruff-Pak DS (2006) Stereological estimation of Purkinje neuron number in $\mathrm{C} 57 \mathrm{BL} / 6$ mice and its relation to associative learning. Neuroscience 141:233-243

Woodruff-Pak DS, Foy MR, Akopian GG, Lee KH, Zach J, Nguyen KP, Comalli DM, Kennard JA, Agelan A, Thompson RF (2010) Differential effects and rates of normal aging in cerebellum and hippocampus. Proc Natl Acad Sci USA 107:1624-1629

Zanjani H, Herrup K, Mariani J (2004) Cell number in the inferior olive of nervous and leaner mutant mice. J Neurogenet 18:327-339

Zhang C, Hua T, Zhu Z, Luo X (2006) Age-related changes of structures in cerebellar cortex of cat. J Biosci 31:55-60

Zhang C, Zhu Q, Hua T (2010) Aging of cerebellar Purkinje cells. Cell Tissue Res 341:341-347 